Provided for non-commercial research and education use. Not for reproduction, distribution or commercial use.

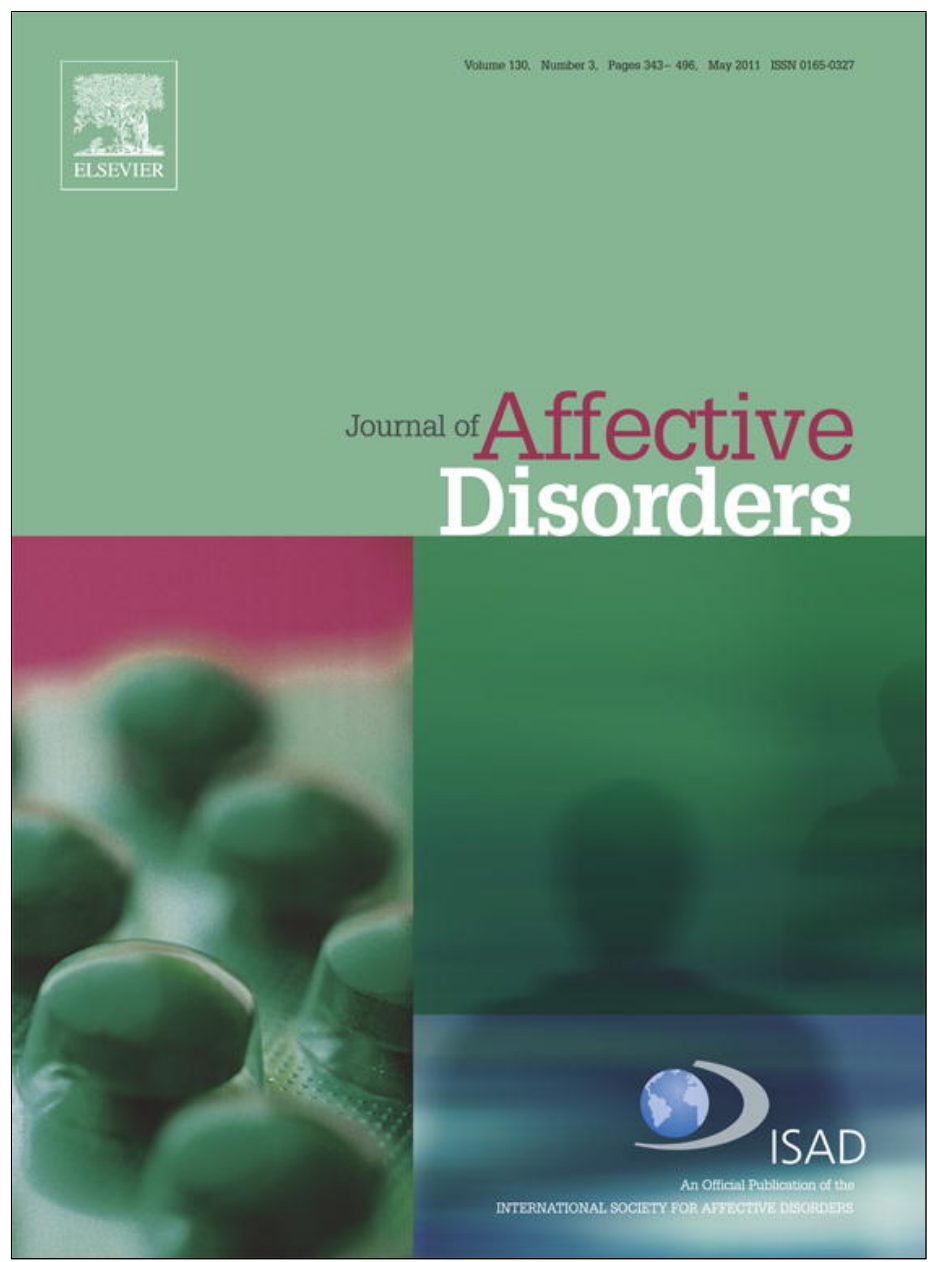

This article appeared in a journal published by Elsevier. The attached copy is furnished to the author for internal non-commercial research and education use, including for instruction at the authors institution and sharing with colleagues.

Other uses, including reproduction and distribution, or selling or licensing copies, or posting to personal, institutional or third party websites are prohibited.

In most cases authors are permitted to post their version of the article (e.g. in Word or Tex form) to their personal website or institutional repository. Authors requiring further information regarding Elsevier's archiving and manuscript policies are encouraged to visit:

http://www.elsevier.com/copyright 
Research report

\title{
Natural course of recurrent psychological distress in adulthood
}

\author{
Markus Jokela $^{\mathrm{a}, \mathrm{b}, \mathrm{c}, *}$, Archana Singh-Manoux $^{\mathrm{a}, \mathrm{d}}$, Martin J. Shipley ${ }^{\mathrm{a}}$, Jane E. Ferrie ${ }^{\mathrm{a}}$, \\ David Gimeno $^{\text {a,e }}$, Tasnime N. Akbaraly a,f, Jenny Head ${ }^{\text {a }}$, Marko Elovainio ${ }^{a, g}$, \\ Michael G. Marmot ${ }^{a}$, Mika Kivimäki a,b,c \\ a Department of Epidemiology and Public Health, University College London, London, UK \\ ${ }^{\mathrm{b}}$ Institute of Behavioural Sciences, University of Helsinki, Helsinki, Finland \\ c Finnish Institute of Occupational Health, Helsinki, Finland \\ d INSERM U687, AP-HP, Paris, France \\ e Division of Environmental and Occupational Health Sciences, School of Public Health, The University of Texas Health Science Center at Houston, Houston, TX, USA \\ ${ }^{\mathrm{f}}$ INSERM U888, Montpellier, France \\ g National Institute for Health and Welfare, Helsinki, Finland
}

\section{A R T I C L E I N F O}

\section{Article history:}

Received 31 August 2010

Received in revised form 27 October 2010

Accepted 27 October 2010

Available online 23 November 2010

\section{Keywords:}

Chronic distress

Kindling hypothesis

Longitudinal

Recurrence

\begin{abstract}
A B S T R A C T
Background: The course of major depressive disorder is often characterized by progressing chronicity, but whether this applies to the course of self-reported psychological distress remains unclear. We examined whether the risk of self-reported psychological distress becomes progressively higher the longer the history of distress and whether prolonged history of distress modifies associations between risk markers and future distress.

Methods: Participants were British civil servants from the prospective Whitehall II cohort study ( $n=7934 ; 31.5 \%$ women, mean age 44.5 years at baseline) followed from 1985 to 2006 with repeat data collected in 7 study phases. Psychological distress was assessed with the 30-item General Health Questionnaire (GHQ). Sex, socioeconomic status, marital status, ethnicity, physical activity, alcohol consumption, smoking, and obesity were assessed as risk markers. Results: Recurrent history of psychological distress was associated with a progressively increasing risk of future distress in a dose-response manner. Common risk markers, such as low socioeconomic status, non-White ethnicity, being single, and alcohol abstinence, were stronger predictors of subsequent distress in participants with a longer history of psychological distress. Sex differences in psychological distress attenuated with prolonged distress history. Limitations: The participants were already adults in the beginning of the study, so we could not assess the progressive chronicity of psychological distress from adolescence onwards.

Conclusions: These data suggest that self-reported psychological distress becomes more persistent over time and that a longer prior exposure to psychological distress increases sensitivity to the stressful effects of certain risk markers.
\end{abstract}

(c) 2010 Elsevier B.V. All rights reserved.

\section{Introduction}

Major depressive disorder is characterized by a chronic course with a high risk of recurrence and recurring episodes

\footnotetext{
* Corresponding author. Department of Psychology, University of Helsinki, PO Box 9, Helsinki FIN-00014, Finland.

E-mail address: markus.jokela@helsinki.fi (M. Jokela).
}

predict progressively increasing risk of subsequent episodes (American-Psychiatric-Association, 2000; Hermens et al., 2004; Mitchell and Subramaniam, 2005; Mueller et al., 1999; Solomon et al., 2000). The initial onset of clinical depression is often preceded by major stressful life events, but subsequent, recurrent episodes appear to be less closely tied to such psychosocial stressors (Monroe and Harkness, 2005; Stroud et al., 2008). This may be due to recurrent depression acquiring an endogenous course that becomes increasingly independent 
of environmental influences over time (stress autonomy model). On the other hand, recurrent episodes of depression may heighten a person's sensitivity to minor stressors of daily life that are encountered more frequently than major life events (stress sensitization model) (Monroe and Harkness, 2005; Post, 1992; Segal et al., 1996; Stroud, et al., 2008).

Self-reported mental health problems are often characterized by co-morbid symptoms of depression, anxiety and somatic complaints (Prince et al., 2007), which may not always be severe enough to meet clinical diagnostic criteria but may nevertheless cause significant impairment (Judd et al., 2002). Subclinical psychological distress shares some characteristics with more severe depressive disorders (Judd, et al., 2002; Kessler et al., 1997; Lewinsohn et al., 2000); for discussion, see (Coyne, 1994; Flett et al., 1997; Solomon et al., 2001). However, it remains unknown whether psychological distress is characterized by (a) progressively increasing chronicity over time and (b) a change in relationships with common depressogenic risk markers as a function of prior distress.

We assessed the cumulative patterns of psychological distress and their interactions with common sociodemographic and health-behavior related risk markers, including sex, socioeconomic status (SES), marital status, ethnicity, physical activity, smoking, alcohol consumption, and obesity. Such risk markers may correlate with exposure to environmental stressors or with capability of coping with such stressors and distress in general (e.g., Hatch and Dohrenwend, 2007; McLeod and Kessler, 1990; Puhl et al., 2008), so their associations with future psychological distress may also be modified by prior history of recurrent distress.

\section{Methods}

\subsection{Participants}

The participants were from the Whitehall II cohort study (Marmot and Brunner, 2005; Marmot et al., 1991). At baseline in 1985-1988, the target population was all London-based office staff ( $n=10308$; 6895 men, 3413 women), aged $35-55$ years, working in 20 civil service departments. Here we used data from all the study phases that included a measurement of psychological distress, i.e., phases 1 (1985-1988), 2 (1989-1990), 3 (19911993), 5 (1997-1999), 6 (2001), 7 (2002-2004), and 8 (2006). At each phase, we included participants who had data on all measurements of the GHQ questionnaire up to that phase and at the next phase (7934 participants providing a total of 35282 observations; for a detailed description of inclusion criteria, see the statistical analysis section below). Informed Ethical approval for the Whitehall II study was obtained from the University College London Medical School committee on the ethics of human research, and the participants gave informed consent.

\subsection{Psychological distress}

Psychological distress was assessed using the 30-item selfadministered General Health Questionnaire (GHQ; Goldberg, 1972; Goldberg et al., 1997; Huppert and Whittington, 1995; Pevalin, 2000; Stansfeld and Marmot, 1992). The items tap into symptoms of depressive, anxiety, neurotic, and stress-related disorders experienced "over the past few weeks." Each item was scored either 1 or 0 to indicate whether the symptom was present or not $(0=$ not at all/no more than usual, $1=$ rather more than usual/much more than usual), and individuals with a total score of 5 or more as GHQ 'cases' $(\mathrm{GHQ}=1)$ and those scoring 0-4 as 'non-cases' $(\mathrm{GHQ}=0)$. This cut-off threshold was determined to be optimal in the Whitehall II cohort, with sensitivity of $73 \%$ and specificity of $78 \%$ against the Clinical Interview Schedule (Stansfeld and Marmot, 1992).

\subsection{Sociodemographic and behavior-related risk markers}

Sociodemographic risk markers included sex, socioeconomic status (SES; civil service occupational grade, $0=$ low, $1=$ intermediate, $2=$ high $)$, ethnicity ( $0=$ white, $1=$ other $)$, and marital status $(0=$ married, $1=$ single, $2=$ divorced $/$ separated, 3 = widowed). Behavior-related measures included physical activity (weekly hours of moderate and vigorous physical activity summed together and divided into tertiles at each phase, $0=$ low, $1=$ intermediate, $2=$ high), smoking $(0=$ non-smoker, $1=$ smoker $)$, alcohol consumption $[0=$ no alcohol, $1=$ moderate alcohol consumption ( $\leq 14$ units/week in women and $\leq 21$ units/week in men), $2=$ heavy alcohol consumption ( $>14$ units/week in women and $>21$ units/week in men), and obesity $(0=$ not obese, $1=$ obese, i.e., body mass index $\geq 30$; height and weight were measured in a medical examination).

Apart from sex and ethnicity, all covariates were coded as time-variant (reported repeatedly at each follow-up phase). Data on BMI were available only at phases $1,3,5$, and 7 , so we replaced missing data at phases 2 and 6 with data from the previous phase. Data on smoking, physical activity, and alcohol use were not available at phase 6 , so missing data at these phases were imputed from data at phase 5 .

\subsection{Statistical analysis}

We assessed whether the cumulative score of GHQ over the first $\mathrm{T}$ phases, $\mathrm{P}_{1}, \mathrm{P}_{2}, \ldots, \mathrm{P}_{\mathrm{T}}$ (exposure) predicted the probability of GHQ caseness at phase $\mathrm{P}_{\mathrm{T}+1}$ (outcome). The creation of the exposure sum-score was carried out for each study phase up to which the participant had no missing measurements of the GHQ. For instance, a participant with a history of GHQ caseness of 0,1 , 1, 0, [missing data, MD], 1, and 1 at phases $1,2,3,5,6,7$, and 8, respectively, would have cumulative exposure scores of $0,1,2,2$, [MD], and [MD] at phases 1, 2, 3, 5, 6, and 7 when predicting GHQ caseness at phases $2,3,5,6,7$, and 8 , respectively (4 personobservations). The cumulative GHQ score ranged from 0 to 6 . There were a total 7934 participants and 35,282 (Table 1).

First we examined the change in the probability of GHQ caseness at phase $\mathrm{P}_{\mathrm{T}+1}$ as a function of cumulative GHQ sum-score at phase $\mathrm{P}_{\mathrm{T}}$ and the number of measurements of the cumulative GHQ score (i.e., the number of study phases) at phase $\mathrm{P}_{\mathrm{T}}$. This analysis was carried out by cross-tabulating the participants by cumulative GHQ score and number of times the cumulative GHQ score was available, and plotting the proportion of GHQ cases for each group.

The association between risk markers and GHQ caseness was examined in two parts. First we examined whether the risk markers assessed at phase $\mathrm{P}_{\mathrm{T}}$ predicted GHQ score at phase $\mathrm{P}_{\mathrm{T}+1}$ without considering the interaction between the risk markers and the cumulative GHQ score. Next, we examined the effects associated with the interaction term between the cumulative 
Table 1

Descriptive statistics for the sample.

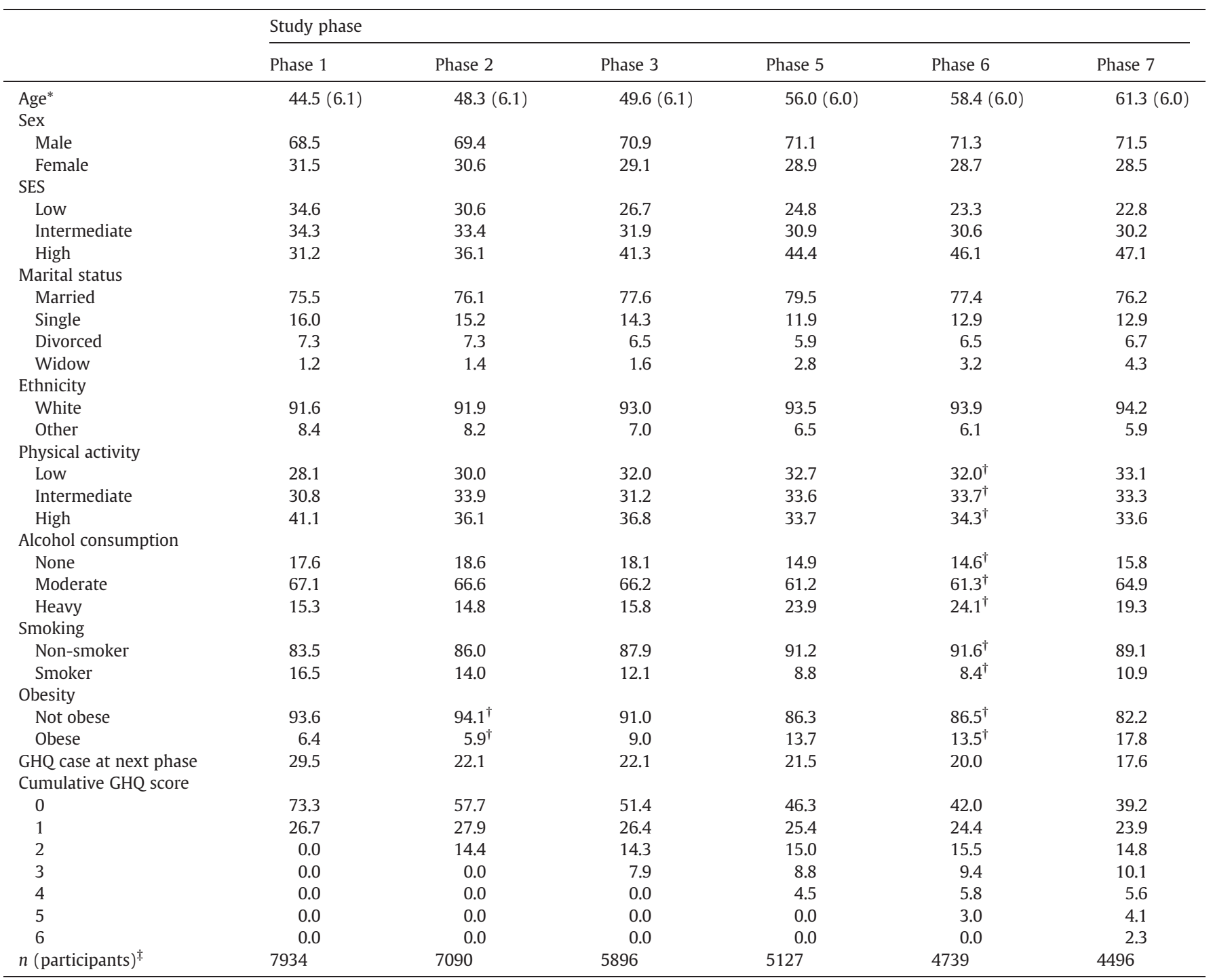

Note: Values are percentages of participants unless otherwise noted. *Values are means (and standard deviations). ${ }^{\dagger}$ Data imputed with data from the previous phase. *Values are numbers of participants. At any given phase $\mathrm{P}_{\mathrm{T}}$ participants were included in the study sample only if they had complete data for GHQ at all phases between $\mathrm{P}_{1}$ and $\mathrm{P}_{\mathrm{T}+1}$.

GHQ score and risk markers at phase $\mathrm{P}_{\mathrm{T}}$ in predicting GHQ caseness at phase $\mathrm{P}_{\mathrm{T}+1}$. These analyses indicated whether the association between risk markers and future GHQ caseness was dependent on cumulative history of GHQ caseness. All models included sex, age, period effects (i.e., follow-up phase), cumulative GHQ score, and the interaction between phase and cumulative GHQ score as independent variables (data not shown). The interaction term between study phase and cumulative GHQ score was included to take into account the observation that the effect of the cumulative GHQ score on future GHQ caseness depended on the number of available measurements of the cumulative GHQ score (see below).

Statistical models were fitted using multilevel, randomintercept logistic regression (Hu et al., 1998; Twisk, 2004) in which each participant contributed cumulative GHQ score observations as described above. All models were fitted using STATA 10 statistical software (StataCorp, College Station, Texas).

\section{Results}

Table 1 shows the descriptive statistics for the sample. The bottom row tabulates the number of participants with a cumulative GHQ score included in the analyses at each phase (data on phase $\mathrm{P}_{\mathrm{T}}$ and phase $\mathrm{P}_{\mathrm{T}+1}$. Fig. 1 shows the probability of being a GHQ case at phase $\mathrm{P}_{\mathrm{T}+1}$ according to cumulative GHQ score and number of measurements of cumulative GHQ score available at phase $\mathrm{P}_{\mathrm{T}}$. The probability of future GHQ caseness increased in a dose-response manner with the number of times a participant had previously been a GHQ case. For example, there were 3028 participants who had 3 measurements of the cumulative GHQ available at phase 3 and had a cumulative GHQ score of 0 at that time. These participants had a $10 \%$ probability of being a GHQ case at the subsequent follow-up. In contrast, of the 466 participants with 3 measurements of the cumulative GHQ by phase 3 and a cumulative GHQ 
score of 3 at that point in time, 59\% were GHQ cases at the next phase. The gradient was steeper with fewer measurement points, which is to be expected; the ratio of high GHQ score per measurement changes as the number of measurement points increases. For instance, a cumulative GHQ score of 3 with 3 measurement times would indicate GHQ caseness at each phase up to that point, while the cumulative score of 3 with 6 measurement times would indicate GHQ caseness only in half of the follow-up phases up to that point.

Next we examined whether the risk markers assessed at phase $\mathrm{P}_{\mathrm{T}}$ predicted GHQ caseness at phase $\mathrm{P}_{\mathrm{T}+1}$ (Table 2, Model 1). The probability of GHQ caseness was higher in women, low SES groups, in single individuals, in those of non-White ethnicity, those undertaking low levels of physical activity, the smokers and the obese. Model 2 of Table 2 shows the effect of each risk marker among participants with a cumulative GHQ score of 0 (main effect) and the proportional change in this effect associated with a one unit increase in the cumulative GHQ score (interaction effect). The interaction effect indicates whether the association between the risk markers and future GHQ depended on the prior cumulative GHQ score. For example, the main effect of sex shows that among participants with a cumulative GHQ score of 0 , women have a 38\% increased odds of becoming a GHQ case at the next phase, compared with men. However, the significant inter- action effect indicates that this increased odds decreases by a factor of 0.95 for each unit increase in the cumulative GHQ score. For participants with a cumulative GHQ score of 6 , for example, the odds ratio for women compared to men of being a GHQ case at phase 8 is only $1.01\left(=1.38 \times(0.95)^{6}\right)$.

There were statistically significant interactions for 5 of the 8 risk markers. The interaction effects of Table 2 are illustrated in Figs. 2 and 3 which plot the estimated probabilities of being a GHQ case for each risk marker according to the cumulative GHQ score. Note that these lines have a slightly different shape than the lines in Fig. 1, because in Figs. 2 and 3 the predictions are calculated over all measurement times combined. Low SES, non-White ethnicity, being single, and alcohol abstinence predicted future GHQ caseness more strongly in individuals with a longer history of GHQ caseness than in individuals with no such history. The nature of these GHQ history-dependent association was similar to the main effects presented in Model 1, with one exception: compared to being married, divorce was associated with a lower risk of future GHQ caseness among individuals with a high cumulative GHQ score, although among individuals with a cumulative GHQ score of 0 , divorce was associated with $16 \%$ higher risk of future GHQ caseness (Model 1, Table 2).

The opposite pattern was observed for sex, as women had a higher risk of GHQ caseness than men among participants with

Table 2

Predicting the probability of GHQ caseness at study phase $\mathrm{P}_{\mathrm{T}+1}$ by sociodemographic and behavior-related risk markers assessed at phase $\mathrm{P}_{\mathrm{T}}$.

\begin{tabular}{|c|c|c|c|}
\hline & \multirow{2}{*}{$\frac{\text { Model } 1}{\text { Main effect }^{\dagger}}$} & \multicolumn{2}{|l|}{ Model 2} \\
\hline & & Main effect ${ }^{\dagger}$ & Interaction effect ${ }^{\dagger \dagger}$ \\
\hline \multicolumn{4}{|l|}{ Sex } \\
\hline Male & (Reference) & (Reference) & (Reference) \\
\hline Female & $1.29^{* * *}(1.21-1.37)$ & $1.38^{* * *}(1.27-1.50)$ & $0.95^{*}(0.90-1.00)$ \\
\hline \multicolumn{4}{|l|}{ SES } \\
\hline Low & (Reference) & (Reference) & (Reference) \\
\hline Intermediate & $0.92 *(0.85-0.99)$ & $1.01(0.91-1.12)$ & $0.88^{* * *}(0.83-0.94)$ \\
\hline High & $0.90^{* *}(0.83-0.97)$ & $1.04(0.94-1.15)$ & $0.83^{* * *}(0.79-0.89)$ \\
\hline \multicolumn{4}{|l|}{ Marital status } \\
\hline Married & (Reference) & (Reference) & (Reference) \\
\hline Single & $1.09 *(1.01-1.18)$ & $1.01(0.90-1.12)$ & $1.09 *(1.01-1.16)$ \\
\hline Divorced & $0.99(0.88-1.10)$ & $1.16(1.00-1.35)$ & $0.87^{* *}(0.80-0.95)$ \\
\hline Widow & $0.97(0.79-1.19)$ & $1.14(0.86-1.51)$ & $0.92(0.80-1.05)$ \\
\hline \multicolumn{4}{|l|}{ Ethnicity } \\
\hline White & (Reference) & (Reference) & (Reference) \\
\hline Other & $1.17^{*}(1.05-1.30)$ & $1.03(0.90-1.19)$ & $1.17^{* *}(1.06-1.29)$ \\
\hline \multicolumn{4}{|l|}{ Physical activity } \\
\hline Low & (Reference) & (Reference) & (Reference) \\
\hline Intermediate & $0.87^{* * *}(0.82-0.94)$ & $0.93(0.84-1.02)$ & $0.96(0.90-1.01)$ \\
\hline High & $0.84^{* * *}(0.78-0.90)$ & $0.87^{* *}(0.79-0.96)$ & $0.99(0.93-1.05)$ \\
\hline \multicolumn{4}{|c|}{ Alcohol consumption } \\
\hline None & (Reference) & (Reference) & (Reference) \\
\hline Moderate & $0.94(0.87-1.02)$ & $1.09(0.99-1.21)$ & $0.87^{* * *}(0.81-0.93)$ \\
\hline Heavy & $0.91(0.83-1.01)$ & $1.06(0.93-1.21)$ & $0.88^{* *}(0.82-0.96)$ \\
\hline \multicolumn{4}{|l|}{ Smoking } \\
\hline Non-smoker & (Reference) & (Reference) & (Reference) \\
\hline Smoker & $1.13^{* *}(1.04-1.23)$ & $1.13^{*}(1.01-1.26)$ & $1.01(0.94-1.09)$ \\
\hline \multicolumn{4}{|l|}{ Obesity } \\
\hline Not obese & (Reference) & (Reference) & (Reference) \\
\hline Obese & $1.11^{*}(1.01-1.23)$ & $1.08(0.95-1.24)$ & $1.04(0.97-1.12)$ \\
\hline
\end{tabular}

Note: ${ }^{* * *} p<.001,{ }^{* *} p<.01,{ }^{*} p<.05$. All models are multilevel logistic regression models fitted separately for each risk marker and adjusted for age, sex, period, cumulative GHQ history score, and interaction effect between period and cumulative GHQ history score. Model 1 includes only main effects, and model 2 includes main effects and interaction effects between risk markers and cumulative GHQ history score. ${ }^{\dagger}$ The main effect estimates show odds ratios (and $95 \%$ confidence intervals) associated with a one unit change in the independent variable. In model 2, the main effect is shown for participants who have a cumulative GHQ score of 0 . "The interaction estimates show the proportional change in the main effect associated with a unit increase in the cumulative GHQ history score. The interaction effects of model 2 are illustrated in Figs. 2 and 3. 


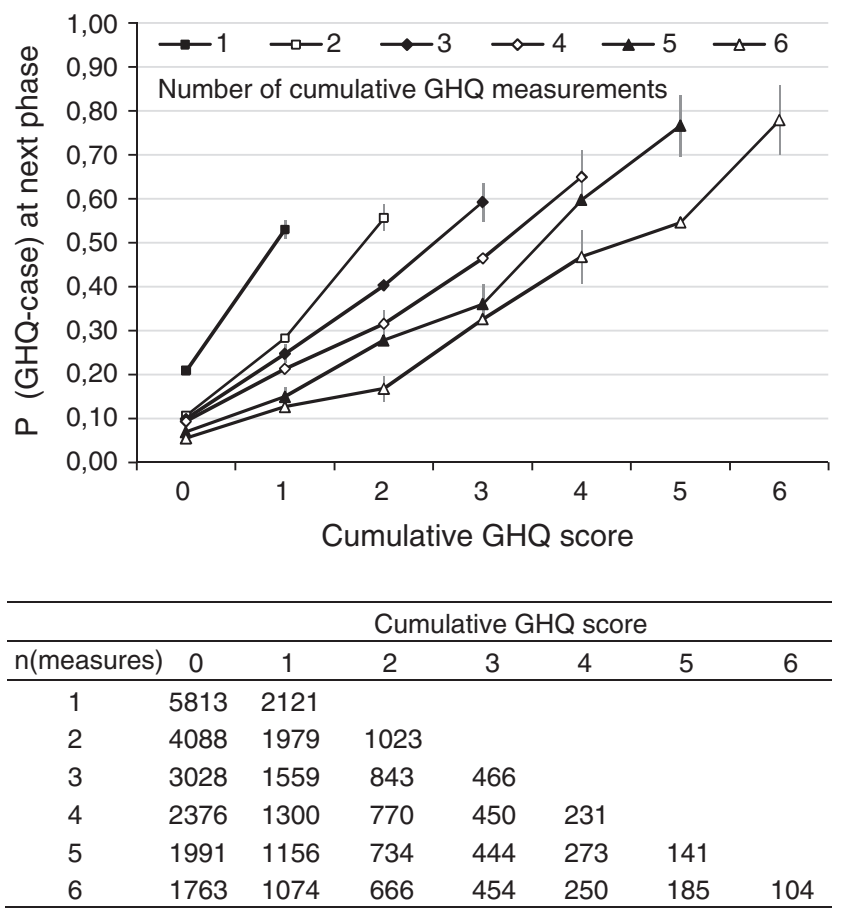

Fig. 1. Probability $(\mathrm{P})$ of being a GHQ case at Phase $\mathrm{P}_{\mathrm{T}+1}$ according to cumulative GHQ score and number of measurements of the cumulative GHQ score available at phase $\mathrm{P}_{\mathrm{T}}$. The error bars are $95 \%$ confidence intervals. The table below the figure shows the number of observations used in the calculation of each probability ( $n=7934$ participants; 35,282 person-observations).
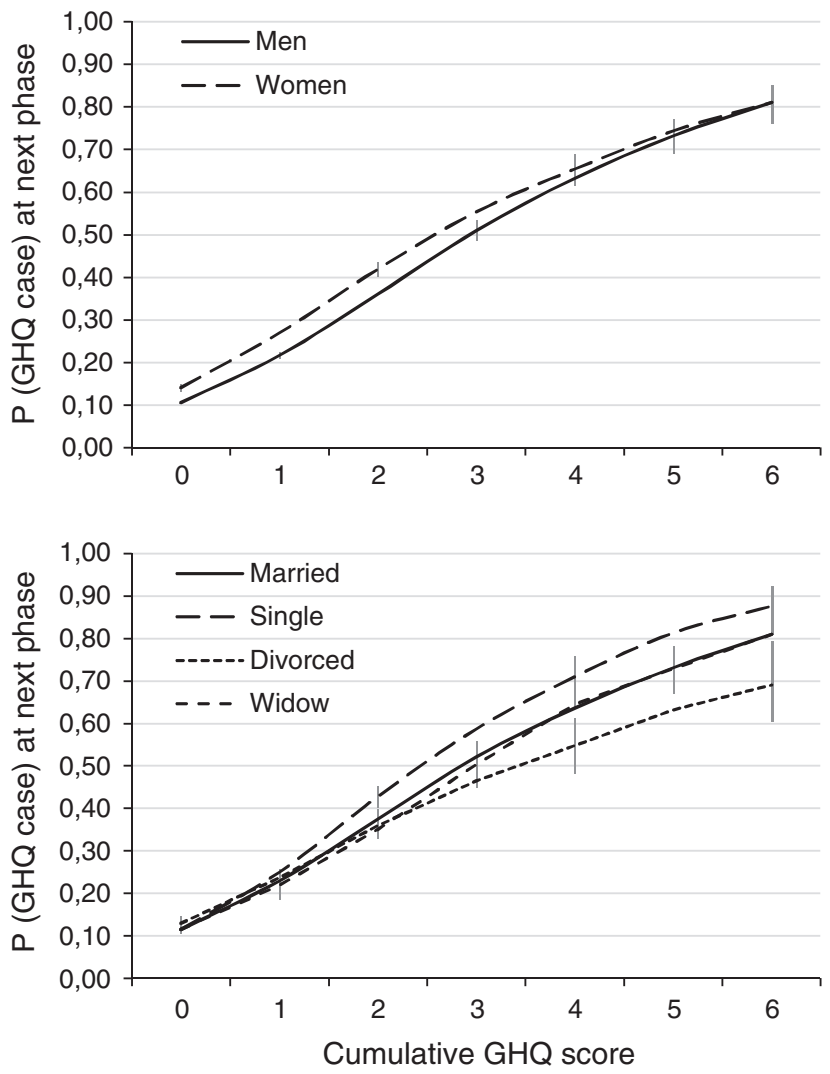

no or only a short history of GHQ caseness but this sex difference was not observed among participants with a long history of GHQ caseness. The influence of physical activity, smoking, and obesity on the probability of being a GHQ case at the next phase was not modified by GHQ history. When all the statistically significant risk markers were mutually adjusted in a single multivariate model, all the interaction effects remained statistically significant with the exception of ethnicity ( $\mathrm{OR}=1.09, \mathrm{CI}=0.98-1.22$; data not shown).

\subsection{Attrition analysis}

To examine potential bias due to selective attrition, we created a dichotomous variable indicating whether the participant had data at phase $\mathrm{P}_{\mathrm{T}+1}(0=$ data, $1=$ no data $)$. We then examined whether this probability was dependent on GHQ caseness at phase $\mathrm{P}_{\mathrm{T}}$ and cumulative GHQ score at phase $\mathrm{P}_{\mathrm{T}}$ in separate models, also including sex, age, and period. Increased probability of attrition was predicted by GHQ caseness ( $\mathrm{OR}=1.14, \mathrm{CI}=1.06-1.22, p<0.001)$ but not by cumulative GHQ score $(\mathrm{OR}=1.01, \mathrm{Cl}=0.98-1.05, p=0.51)$, indicating that GHQ cases were more likely than non-cases to be lost during the follow-up. This might have led to some underestimation of the cumulative effect of prior GHQ caseness on future risk, because the number of participants with high GHQ scores was lower than it would have been without selective attrition. When the interaction effects shown in Table 2 were fitted in a subsample with complete data at all of the study phases ( $n=4496$ participants, 26976 observations), the results closely resembled the main results, with the exception of a non-
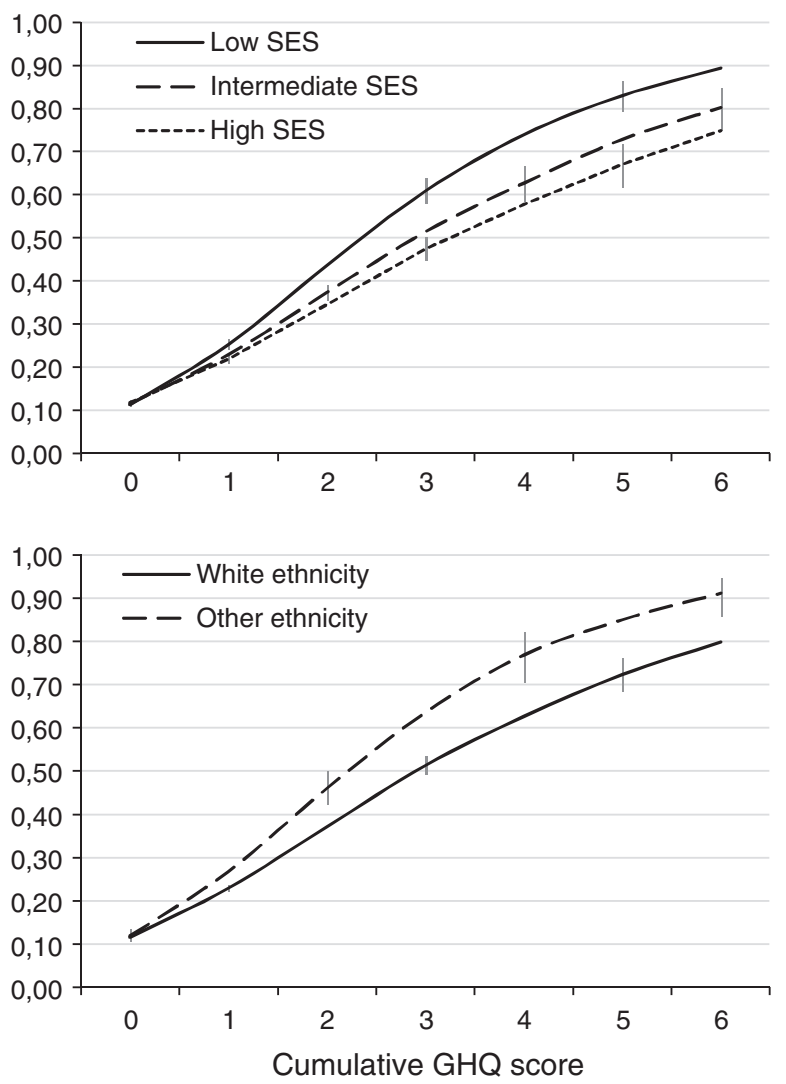

Fig. 2. Model-predicted probability (P) of GHQ caseness at phase $\mathrm{P}_{\mathrm{T}+1}$ as a function of sociodemographic risk markers and cumulative GHQ score at phase $\mathrm{P}_{\mathrm{T}}$. The error bars are $95 \%$ confidence intervals. See the interaction effects of Table 2 for statistical details. $n=7934$ participants, 35,282 person-observations. 

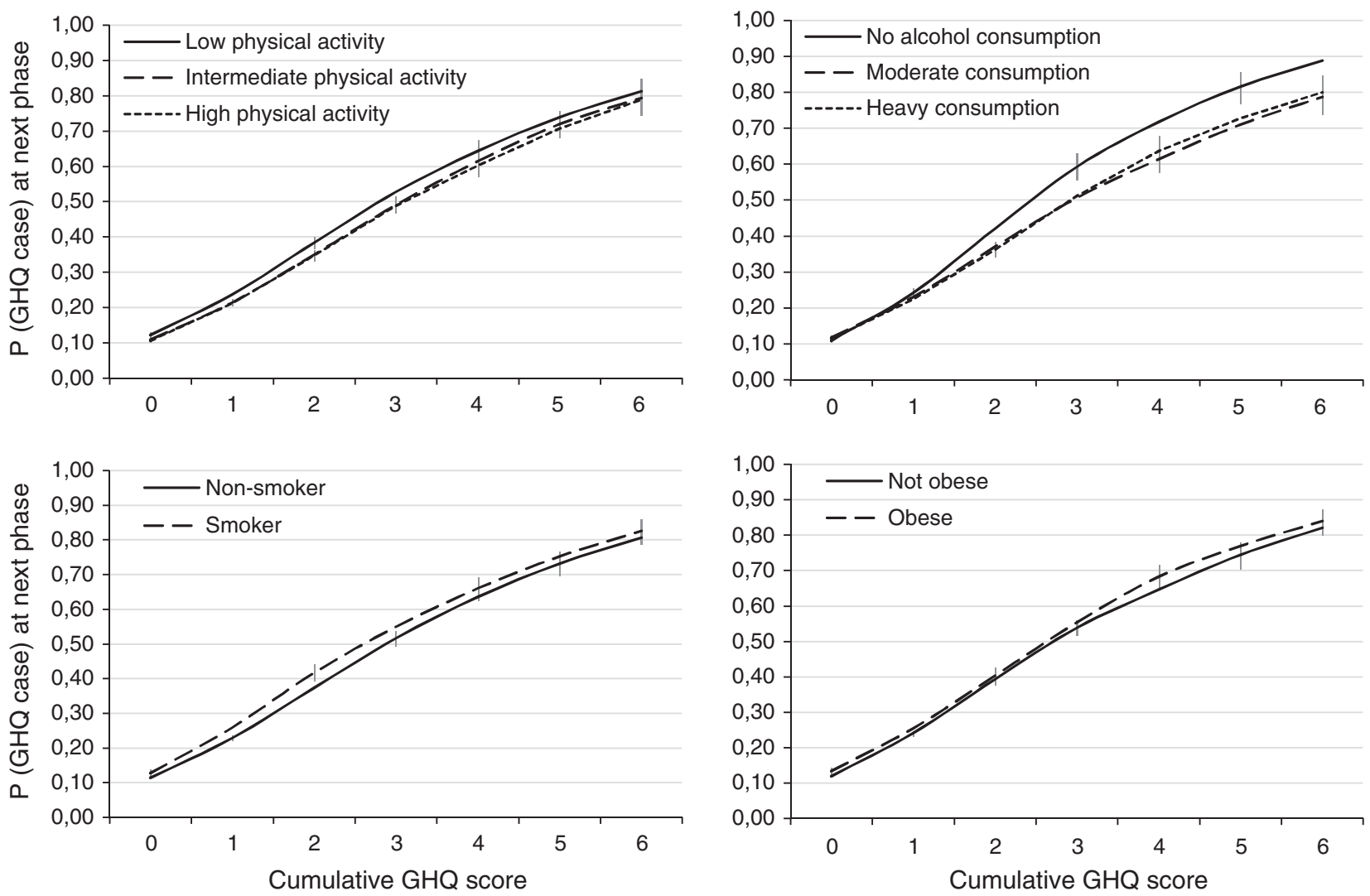

Fig. 3. Model-predicted probability (P) of GHQ caseness at phase $\mathrm{P}_{\mathrm{T}+1}$ as a function of health-related risk markers and cumulative GHQ score at phase $\mathrm{P}_{\mathrm{T}}$. The error bars are $95 \%$ confidence intervals. See the interaction effects of Table 2 for statistical details. $n=7934$ participants, 35,282 person-observations.

significant interaction effect for ethnicity in the complete-case analysis ( $\mathrm{OR}=1.09, \mathrm{CI}=0.97-1.22$; data not shown), suggesting that the interaction effects were not substantially affected by attrition bias.

\section{Discussion}

The present study has two main findings. First, a cumulative history of self-reported psychological distress strongly conditioned the likelihood of future psychological distress, such that recurrent distress became progressively more persistent over time. Thus, participants who exhibited GHQ caseness at all of 5 or 6 measurement times over an observation period of two decades had approximately an $80 \%$ probability of exhibiting GHQ caseness 2 years later whereas the corresponding probability was only $6 \%$ in participants with no prior distress. These findings suggest that symptoms of self-reported psychological distress exhibit a similar progressively accumulating pattern as that observed for episodes of major depressive disorder in clinical samples (Solomon et al., 2000).

Second, a cumulative history of psychological distress modified the effects of socioeconomic and behavior-related risk markers on future distress. SES, ethnicity, marital status, and alcohol abstinence became stronger predictors of future GHQ caseness in participants with a longer history of GHQ caseness, suggesting that chronic distress may render individuals more vulnerable to risk markers and their correlates. This is analogous to the process postulated by the stress sensitization model, according to which prior episodes of depression sensitize individuals to minor stressors of daily life (Monroe and Harkness, 2005).

\subsection{Comparison with previous studies}

Most of the interaction effects between cumulative GHQ and risk markers were in the expected directions, e.g., increasing risk of GHQ caseness was associated with a combination of prior distress and low SES or ethnic minority origin. Parental SES has been shown to predict recurrent adult depression (Gilman et al., 2003), which is consistent with our findings. Other studies of adult SES have found no evidence of SES being related to risk of recurring episodes (Belsher and Costello, 1988; Burcusa and Iacono, 2007; Gonzales et al., 1985), but most of these studies have been carried out in relatively small and underpowered samples. Ethnic differences have been little studied in relation to recurrence.

Marriage had a protective effect against accumulating psychological distress, which was expected in light of the health benefits of being married (Stack and Eshleman, 1998). Perhaps surprisingly, however, prior history of GHQ caseness predicted future GHQ caseness less strongly in divorced participants than in married or single participants. Although divorced individuals often have poorer health, an increasing number of longitudinal studies show that becoming divorced may actually increase subjective well-being - or at least attenuate distress that has built up years before the break-up (Andress and Brockel, 2007; Booth and Amato, 1991; Gardner and Oswald, 2006). Our finding suggests that divorce may 
attenuate the association between past and future distress, perhaps because it represents a discontinuity in a person's life.

Alcohol consumption was also protective, which is in agreement with a number of studies suggesting that, compared to abstinence, moderate alcohol consumption is associated with mental and other health benefits (Britton et al., 2004; Goldberg, 2003; McDougall et al., 2007; O'Donnell et al., 2006; Peele and Brodsky, 2000). In the present sample even heavy alcohol consumption had a beneficial effect, which contrasts with most other studies reporting an inverse J-shaped curve between alcohol consumption and mental health (O'Donnell, et al., 2006; Peele and Brodsky, 2000). As the participants worked in the British Civil Service, it is likely that the prevalence of problem drinking was lower in this cohort than seen in population-based samples.

Gender exhibited the opposite pattern to other risk markers discussed above; the increased risk of psychological distress in women compared to men was observed in participants who had no or only a short history of GHQ caseness but was absent among participants with a chronic history of GHQ caseness. The gender difference in depression and psychological distress is well-established (Boughton and Street, 2007; Davis et al., 1999; Hyde et al., 2008), but the rate of depression recurrence seems to be equal in men and women (Burcusa and Iacono, 2007; Luijendijk et al., 2008). Our finding implies that the gender difference in psychological distress may diminish with increasing chronicity of distress.

The effects of physical activity, smoking, and obesity were not modified by GHQ caseness history even though these risk markers did predict GHQ caseness in the expected manner when examined in the absence of the interaction effect with prior GHQ caseness. Thus, the moderating influence of prior psychological distress on the effect of different kinds of mental health risk markers included in our study was more apparent in relation to sociodemographic markers than behavior-related risk markers.

While our findings suggest similarities between clinical depression and self-reported psychological distress, some differences between the two need to be acknowledged. First, the recurrence of clinical depression is measured as discrete depressive episodes. We operationalized the recurrence of psychological distress using 6 repeated measurements collected over a period of 19 years. As individual differences in psychological distress exhibit moderate continuity over time, it is possible that a cumulative measure captures different levels of latent chronicity that become apparent with repeated measurements rather than the causal effects (sensitization) of prior distress on subsequent distress.

Second, the original stress autonomy and sensitization models are concerned with major life events that can trigger depressive episodes (Monroe and Harkness, 2005; Stroud, et al., 2008). We examined common sociodemographic and behavior-related health markers that are constant (sex, ethnicity) or at least moderately stable over time (e.g., marital status, obesity) and thereby cannot function as triggering events as such. Some of these risk markers might act as proxy measures of the frequency and severity with which individuals encounter major and minor life stressors and indicate their capability to deal with them. For example, ethnic minority status and low SES have been related to increased exposure to stressful environments (Hatch and Dohrenwend, 2007), which may explain their interaction effects with psychological distress history. They may also have independent effects mediated by other mechanisms besides stressful life events.

\subsection{Methodological considerations}

A large sample size and repeated measurements from 7 study phases provided us with a strong longitudinal setting in which to assess the recurrent nature of psychological distress. However, there are limitations to this study. First, some of the missing covariate data had to be imputed with data from the previous study phase. This might have somewhat decreased the accuracy of the covariate data, but it is unlikely that this had a substantial effect as the imputation was applied only to one (for smoking, physical activity, and alcohol consumption) or two (for body mass index) study phases. Second, the Whitehall II sample consists mainly of white-collar civil servants and is not representative of the general population, which may limit the generalizability of the results. Third, all participants were over 30 years of age at the beginning of the study, so we could not assess the accumulation of psychological distress from adolescence when symptoms of depression and anxiety often begin to emerge (Kessler et al., 2005). Studies in younger populations are needed to further understand the timing of cumulative effects. Lastly, detailed data on diagnosed and treated clinical psychiatric disorders were unavailable, so we could not assess the influence of treatment of the recurrent course of psychological distress. At Phase 7, 3.5\% of the participants reported using anti-depressive or anti-anxiety medication, suggesting that the prevalence of clinical depression or anxiety in the sample was relatively low and that treatment was unlikely to substantially bias the overall results.

\subsection{Conclusions}

With the limitations of our study in mind, we conclude that the recurrent course of self-reported psychological distress in non-clinical populations qualitatively resembles that of recurring episodes of major depressive disorder in patient samples. The findings also suggest that a process similar to that postulated by the stress sensitization model may generalize beyond major life events, so that chronic distress heightens individuals' sensitivity to a range of common risk markers. These findings add evidence to support a continuum between subclinical symptoms and clinical disorders, and underscore the need for further research on the course, prognosis, and recurrence of psychological distress.

\section{Role of funding source}

The study sponsors had no further role in study design; in the collection, analysis and interpretation of data; in the writing of the report; and in the decision to submit the paper for publication.

\section{Conflict of interest}

None of the authors have any conflicting interests, financial or otherwise.

\section{Acknowledgements}

The Whitehall II study has been supported by grants from the British Medical Research Council (MRC); the British Heart Foundation; the British Health and Safety Executive; the British Department of Health; the National Heart, Lung, and Blood 
Institute (grant HL36310); the National Institute on Aging (grant AG13196); the Agency for Health Care Policy and Research (grant HS06516); and the John D. and Catherine T. Mac Arthur Foundation Research Networks on Successful Midlife Development and Socioeconomic Status and Health. M.K. was supported by the Academy of Finland (grants no: 117604, 124322, and 124271). J.E.F. was supported by the Medical Research Council (grant G8802774), A.S.M. by a "European Young Investigator Award" by the European Science Foundation, M.J.S. by the British Heart Foundation and M.G.M. by an MRC Research Professorship.

\section{References}

American-Psychiatric-Association, 2000. Diagnostic and statistical manual of mental disorders, 4th edition. APA, Washington, DC.

Andress, H.J., Brockel, M., 2007. Income and life satisfaction after marital disruption in Germany. Journal of Marriage and the Family 69 (2), 500-512.

Belsher, G., Costello, C.G., 1988. Relapse after recovery from unipolar depression - A critical review. Psychological Bulletin 104 (1), 84-96.

Booth, A., Amato, P., 1991. Divorce and psychological stress. Journal of Health and Social Behavior 32 (4), 396-407.

Boughton, S., Street, H., 2007. Integrated review of the social and psychological gender differences in depression. Australian Psychologist 42 (3), 187-197.

Britton, A., Singh-Manoux, A., Marmot, M., 2004. Alcohol consumption and cognitive function in the Whitehall II study. American Journal of Epidemiology 160 (3), 240-247.

Burcusa, S.L., Iacono, W.G., 2007. Risk for recurrence in depression. Clinical Psychology Review 27 (8), 959-985.

Coyne, J.C., 1994. Self-reported distress-analog or ersatz depression. Psychological Bulletin 116 (1), 29-45.

Davis, M.C., Matthews, K.A., Twamley, E.W., 1999. Is life more difficult on mars or venus? A meta-analytic review of sex differences ln major and minor life events. Annals of Behavioral Medicine 21 (1), 83-97.

Flett, G.L., Vredenburg, K., Krames, L., 1997. The continuity of depression in clinical and nonclinical samples. Psychological Bulletin 121 (3), 395-416.

Gardner, J., Oswald, A.J., 2006. Do divorcing couples become happier by breaking up? Journal of the Royal Statistical Society Series A-Statistics in Society 169, 319-336.

Gilman, S.E., Kawachi, I., Fitzmaurice, G.M., Buka, S.L., 2003. Socio-economic status, family disruption and residential stability in childhood: relation to onset, recurrence and remission of major depression. Psychological Medicine 33 (8), 1341-1355.

Goldberg, D.P., 1972. Detecting pychiatric illness by questionnaire. Oxford University Press, London.

Goldberg, I.J., 2003. To drink or not to drink? The New England Journal of Medicine 348 (2), 163-164.

Goldberg, D.P., Gater, R., Sartorius, N., Ustun, T.B., Piccinelli, M., Gureje, O., et al., 1997. The validity of two versions of the GHQ in the WHO study of mental illness in general health care. Psychological Medicine 27 (1), 191-197.

Gonzales, L.R., Lewinsohn, P.M., Clarke, G.N., 1985. Longitudinal follow-up of unipolar depressives - An investigation of predictors of relapse. Journal of Consulting and Clinical Psychology 53 (4), 461-469.

Hatch, S.L., Dohrenwend, B.P., 2007. Distribution of traumatic and other stressful life events by race/ethnicity, gender, SES and age: a review of the research. American Journal of Community Psychology 40 (3-4), 313-332.

Hermens, M.L.M., van Hout, H.P.J., Terluin, B., van der Windt, D., Beekman, A.T.F., van Dyck, R., et al., 2004. The prognosis of minor depression in the general population: a systematic review. General Hospital Psychiatry 26 (6), 453-462.

Hu, F.B., Goldberg, J., Hedeker, D., Flay, B.R., Pentz, M.A., 1998. Comparison of population-averaged and subject-specific approaches for analyzing repeated binary outcomes. American Journal of Epidemiology 147 (7), 694-703.

Huppert, F.A., Whittington, J.E., 1995. Symptoms of psychological distress predict 7-year mortality. Psychological Medicine 25 (5), 1073-1086

Hyde, J.S., Mezulis, A.H., Abramson, L.Y., 2008. The ABCs of depression: integrating affective, biological, and cognitive models to explain the emergence of the gender difference in depression. Psychological Review 115 (2), 291-313.

Judd, L.L., Schettler, P.J., Akiskal, H.S., 2002. The prevalence, clinical relevance, and public health significance of subthreshold depressions. The Psychiatric Clinics of North America 25 (4), 685-698.
Kessler, R.C., Zhao, S.Y., Blazer, D.G., Swartz, M., 1997. Prevalence, correlates, and course of minor depression and major depression in the national comorbidity survey. Journal of Affective Disorders 45 (1-2), 19-30.

Kessler, R.C., Berglund, P., Demler, O., Jin, R., Walters, E.E., 2005. Lifetime prevalence and age-of-onset distributions' of DSM-IV disorders in the national comorbidity survey replication. Archives of General Psychiatry 62 (6), 593-602.

Lewinsohn, P.M., Solomon, A., Seeley, J.R., Zeiss, A., 2000. Clinical implications of "subthreshold" depressive symptoms. Journal of Abnormal Psychology 109 (2), 345-351.

Luijendijk, H.J., van den Berg, J.F., Dekker, M., van Tuijl, H.R., Otte, W., Smit, F., et al., 2008. Incidence and recurrence of late-life depression. Archives of General Psychiatry 65 (12), 1394-1401.

Marmot, M., Brunner, E., 2005. Cohort profile: the Whitehall II study. International Journal of Epidemiology 34 (2), 251-256.

Marmot, M.G., Smith, G.D., Stansfeld, S., Patel, C., North, F., Head, J., et al., 1991. Health inequalities among British civil-servants - The Whitehall II study. Lancet 337 (8754), 1387-1393.

McDougall, G.J., Becker, H., Delville, C.L., Vaughan, P.W., Acee, T.W., 2007. Alcohol use and older adults: a little goes a long way. International Journal on Disability and Human Development 6 (4), 431-440.

McLeod, J.D., Kessler, R.C., 1990. Socioeconomic-status differences in vulnerability to undesirable life events. Journal of Health and Social Behavior 31 (2), 162-172.

Mitchell, A.J., Subramaniam, H., 2005. Prognosis of depression in old age compared to middle age: a systematic review of comparative studies. The American Journal of Psychiatry 162 (9), 1588-1601.

Monroe, S.M., Harkness, K.L., 2005. Life stress, the "Kindling" hypothesis, and the recurrence of depression: considerations from a life stress perspective. Psychological Review 112 (2), 417-445.

Mueller, T.I., Leon, A.C., Keller, M.B., Solomon, D.A., Endicott, J., Coryell, W., et al., 1999. Recurrence after recovery from major depressive disorder during 15 years of observational follow-up. The American Journal of Psychiatry 156 (7), 1000-1006.

O'Donnell, K., Wardle, J., Dantzer, C., Steptoe, A., 2006. Alcohol consumption and symptoms of depression in young adults from 20 countries. Journal of Studies on Alcohol 67 (6), 837-840.

Peele, S., Brodsky, A., 2000. Exploring psychological benefits associated with moderate alcohol use: a necessary corrective to assessments of drinking outcomes? Drug and Alcohol Dependence 60 (3), 221-247.

Pevalin, D.J., 2000. Multiple applications of the GHQ-12 in a general population sample: an investigation of long-term retest effects. Social Psychiatry and Psychiatric Epidemiology 35 (11), 508-512.

Post, R.M., 1992. Transduction of psychosocial stress into the neurobiology of recurrent affective disorder. The American Journal of Psychiatry 149 (8), 999-1010.

Prince, M., Patel, V., Saxena, S., Maj, M., Maselko, J., Phillips, M.R., et al., 2007. Global mental health 1-no health without mental health. Lancet 370 (9590), 859-877.

Puhl, R.M., Andreyeva, T., Brownell, K.D., 2008. Perceptions of weight discrimination: prevalence and comparison to race and gender discrimination in America. International Journal of Obesity 32 (6), 992-1000.

Segal, Z.V., Williams, J.M., Teasdale, J.D., Gemar, M., 1996. A cognitive science perspective on kindling and episode sensitization in recurrent affective disorder. Psychological Medicine 26 (2), 371-380.

Solomon, D.A., Keller, M.B., Leon, A.C., Mueller, T.I., Lavori, P.W., Shea, T., et al., 2000. Multiple recurrences of major depressive disorder. The American Journal of Psychiatry 157 (2), 229-233.

Solomon, A., Haaga, D.A.F. Arnow, B.A., 2001. Is clinical depression distinct from subthreshold depressive symptoms? A review of the continuity issue in depression research. The Journal of Nervous and Mental Disease 189 (8), 498-506.

Stack, S., Eshleman, J.R., 1998. Marital status and happiness: a 17-nation study. Journal of Marriage and the Family 60 (2), 527-536.

Stansfeld, S.A., Marmot, M.G., 1992. Social class and minor psychiatric disorder in British civil servants - A validated screening survey using the General Health Questionnaire. Psychological Medicine 22 (3), 739-749.

Stroud, C.B., Davila, J., Moyer, A., 2008. The relationship between stress and depression in first onsets versus recurrences: a meta-analytic review. Journal of Abnormal Psychology 117 (1), 206-213.

Twisk, J.W.R., 2004. Longitudinal data analysis. A comparison between generalized estimating equations and random coefficient analysis. European Journal of Epidemiology 19 (8), 769-776. 